\title{
Conceitos das Teorias Organizacionais: revisão de literatura
}

\author{
Mario Rosa dos Santos ${ }^{1}$; Manoel Rodrigues Chaves; \\ André Vasconcelos da Silva3; Daniely Rodovalho Macedo ${ }^{4}$
}

\section{Resumo}

O presente texto utiliza-se da técnica de revisão de literatura para fazer uma breve reflexão sobre alguns dos teóricos que retratam a teoria das organizações assim como o estabelecimento da estrutura organizacional. Realiza-se um contraponto entre os pensamentos sobre a interelação das pessoas, sociedade, organização, todos permeados pela comunicação. Trouxemos um breve levantamento das perspectivas sobre os conceitos, visto que, existem na literatura clássica, inúmeros teóricos sobre o assunto. Assim como a valorização das relações entre os trabalhadores e as organizações, mostrando-se peças fundamentais no jogo das organizações, sejam elas de qualquer segmento da cadeia produtiva. Verificamos, também, as novas releituras sobre estas teorias, assim como o que hoje ainda se aplica das mesmas dentro da estrutura da organização. Observando um ponto de fusão, entre os novos pesquisadores, sobre a necessidade de, no caso Brasileiro, o surgimento de "teorias tropicais". Adequando os conceitos administrativos, relacionado às organizações da América latina.

Palavras chave: teorias organizacioanis; estruturas organizacionais e análise das organizações.

1. Sociólogo, aluno do Programa de Mestrado Profissional em Gestão Organizacional da Universidade Federal de Goiás/Regional Catalão, Técnico-Administrativo da Universidade Federal de Goiás/Regional Goiânia. mrosa8@gmail.com

2. Geógrafo, Docente do Programa de Mestrado Profissional em Gestão Organizacional da Universidade Federal de Goiás/Regional Catalão. manoelufg@ gmail.com

3. Professor Doutor no curso de Administração e do Programa de Mestrado Profissional em Gestão Organizacional da Universidade Federal de Goiás/Regional Catalão, Brasil. andre.silva.ufg@gmail.com

4. Enfermeira, aluna do Programa de Mestrado Profissional em Gestão Organizacional da Universidade Federal de Goiás/Regional Catalão, Brasil e docente na faculdade CESUC e SENAC em Catalão/Goiás. danyrmacedo@yahoo.com.br 


\section{Introdução}

A presente revisão de literatura nos mostra ao longo do tempo a diversidade de teorias e como as mesmas evoluíram para chegar à definição do que são organizações, em toda sua complexidade de existência, através de inúmeros autores que vieram ao longo dos anos, refletindo sobre a estrutura e funcionamento destas organizações.

As organizações estão presentes no cotidiano das instituições públicas ou privadas, entidades políticas ou assistenciais. As interações entre as pessoas no meio social ocorrem em algum tipo de organização. Nesse sentido, as organizações estão entrelaçadas nas teias das sociedades contemporâneas e a qualidade de vida do homem depende diretamente de como as organizações funcionam e se organizam. Segundo Bastos, Loiola, Queiroz e Silva (2004), ao analisar organizações como objeto de estudo, depara-se com um campo de estudo fragmentado e disperso, não havendo um consenso quanto à definição de uma organização.

Devido à grande diversificação de enfoques, abordagens e ênfases dados ao conceito de estudos organizacionais, Bastos et. al. (2004), exploram as definições no senso comum e no campo científico. No senso comum afirmam, "usamos o termo organização tanto para designar as ações de construir algo como para descrever as características ou qualidades desse algo construído". Já no terreno científico "essa diversidade de significados se traduz em diferentes perspectivas conceituais e em tentativas explícitas de se encontrar uma definição para o fenômeno".

Corrobora com esta observação Motta (2013, p.02) o principal problema que comporta o campo do conhecimento da administração é o fato de uma ausência epistemológica precisa desta área. Significa, portanto, que a administração recorre outros campos do conhecimento notoriamente mais sistemáticos em nível epistêmico e conceitual (...). O que traz um melhor aporte teórico cercando a teoria das organizações de inúmeros conhecimentos para compreender esse fenômeno.

Nesse sentido Bastos, Loiola, Queiroz e Silva (2004) apresentam algumas considerações relevantes de autores que contribuem para construção do conceito sobre organizações. Para Chester Barnard (1938/1979, apud BASTOS et al 2004) um dos pioneiros do campo dos estudos organizacionais. Para Barnard, as organizações correspondem a sistemas cooperativos, formados por pessoas que comunicam entre si e desenvolvem ações tendo em vista um propósito comum cuja longevidade depende de como são governados. $E$ ainda cita três principais características que distinguem uma organização, que são: a cooperação, a adesão de seus membros com base num propósito comum e a aptidão destes membros para a comunicação.

Estas designadas características seguem presentes nas discussões de demais autores, que durante o decorrer deste texto apresentaremos seus pontos de vista. Além disso, vamos observar o embate teórico sobre o estabelecimento de como os indivíduos se comportam diante da organização, ou seja, se este se adapta aos seus processos, ou se a organização está sensível às influencias dos funcionários.

Segundo Cavalcanti e Alcadipani (2013, p.557) a Teoria Ator-Rede (TAR) tem sido utilizada como uma abordagem epistemológica para se compreender as organizações tanto no exterior quando no Brasil.Este pensamento vem a corroborar com a compreensão necessária, destas relações do individuo com a organização, no qual o mesmo está inserido. Auxiliando na compreensão destas relações. 
Para Rosa (2015, p.187) o histórico das instituições é um conjunto organizado por pessoas com finalidades em comum, as quais formam parte de redes de poder social. A junção se pessoas com os mesmo interesses dentro de uma organização, faz, com que estas relações ganhem magnitude, sendo assim, ganhado poder dentro da organização. O que pode ser utilizado para a tomada de decisão de como esta organização reagirá ao seu agrupamento de mercado.

No campo da ciência contranormal, as organizações são explicadas pelo conhecimento das intenções que estão na base das ações dos indivíduos e grupos que a compõem. Nas organizações, antes a análise se concentrava no que se esperava que as pessoas fizessem, agora se concentram no que efetivamente elas fazem. Assim, os objetivos, a missão, a hierarquia, as descrições de cargos e os procedimentos operacionais deixam de ser percebidos como elementos concretos, tornando-se artefatos simbólicos que refletem o modo com os indivíduos percebem e interpretam a realidade organizacional (FONSECA e MACHADO-DA-SILVA, 1993 apud BASTOS et al, 2004).

Pretendemos trabalhar neste artigo os aspectos estruturais da organização, relacionado com a importância da presença do indivíduo dentro destas organizações, este ponto também sendo objeto de estudo de alguns teóricos. Observando a presença de inferências, que podem ser externas, referentes ao seguimento de negócios que fazem parte, ou interno, quando esta se avaliando os indivíduos e suas organizações. A seguir, discutiremos sobre estes e demais aspectos referentes à uma cultura organizacional.

\section{Conceitos das Teorias Organizacionais}

Motta (2001, p.56 apud BASTOS et al 2004), ao trabalhar os conceitos das teorias organizacionais, busca a ideia de que adotar uma perspectiva racional é um equívoco que é reproduzido por parte expressiva das abordagens no campo de estudos organizacionais. Ao adotar essa perspectiva racional, a maior parte dos modelos de decisão organizacional presume que os objetivos organizacionais constituem dados para os quais os olhares de todos os membros da organização se dirigem com vistas a identificar a melhor forma de alcança-los.

Já em Etzioni (1989, apud BASTOS et al 2004) outro importante teórico organizacional, nos traz a seguinte definição de organização:

São unidades sociais (ou agrupamentos humanos) intencionalmente construídas e reconstruídas, a fim de atingir objetivos específicos. [...] Caracterizam-se por: 1) divisão do trabalho, poder e responsabilidade de comunicação [...] planejadas intencionalmente para identificar a realização de objetivos; 2) a presença de um ou mais centros de poder que controlam os esforços combinados da organização e os dirigem para seus objetivos; 3) substituição de pessoal (etzioni, $1964 / 1989$, p. 3)

Etzioni (1989, apud BASTOS et al 2004) conclui que:

Podemos reservar, sem risco, a palavra organização para unidades planejadas, intencionalmente estruturadas com o propósito de atingir objetivos específicos. (p. 4).

Segundo Stoner e Freeman (1995, apud BASTOS et al 2004) a definição que uma organização existe quando duas ou mais pessoas trabalham juntas e de modo 
estruturado para alcançar um objetivo específico ou um conjunto de objetivos. Através do alcance deste dito objetivo, faz com que os indivíduos formem vínculos com a instituição. Surgindo estudos relacionados aos comprometimento. (Bastos et al, 2004).

Sendo assim, Custodio, Siqueira, Viegas, Pinto e Silva (2013, p.03) o interesse pelo estudo do comprometimento tem sido crescente, o que se percebe tanto na literatura nacional quanto na estrangeira, principalmente. Os teóricos, vem percebendo, ao longo do tempo, na análise das organizações, que a atribuição do vinculo gera comprometimento do trabalhador, sendo positivo para a organização.

A obra Imagens da organização, escrita por Morgan (1996, apud BASTOS et al 2004), trouxe grande impacto para estudos organizacionais. Morgan (1996 apud BASTOS et al 2004) utiliza a noção de metáfora para organizar a multiplicidade de olhares que caracteriza esse campo de estudo. Ele reconhece que as organizações são fenômenos complexos e paradoxais e, portanto, podem ser compreendidos sob muitas perspectivas diferentes.

As metáforas, segundo Morgan (1996, apud BASTOS et al 2004) constituem um recurso importante, pois implicam uma forma de pensar, maneiras de ver que exercem influência sobre as formas de nos expressarmos e, por conseguinte, sobre as nossas construções científicas. Morgan (1996, apud BASTOS et al 2004) ainda apresenta, discute e avalia oito diferentes metáforas (máquina, organismo, cérebro, cultura, sistema político, prisão psíquica, fluxo e transformação e instrumento de dominação) subjacentes às diferentes teorizações sobre organizações.

Diante de tamanha dispersão de entendimento sobre 0 que são as organizações, Mardsen e Townley (2001, apud BASTOS et al 2004) encontram duas abordagens desse fenômeno, que se originam de duas perspectivas distintas sobre ciência e produção do conhecimento: ciência normal e ciência contranormal. A primeira perspectiva, as organizações são consideradas entes empíricos, tangíveis, concretos, que podem, com base em métodos e técnicas quantitativas, ser observados, medidos, conceituados como tais e em relação às suas práticas. Em síntese, Mardsen e Townley (2001, apud BASTOS et al 2004) diz que a organização equivale a uma entidade que pensa, faz, formula estratégias, contrata, demite, lidera, etc. Fonseca e Machado-da-Silva (1993, apud BASTOS et al 2004). Essa entidade passa também a ser adjetivada: pode ser burocrática, moderna, complexa, dinâmica ou competitiva a partir dos elementos que a caracteriza.

Para Hall (1984, apud BASTOS et al 2004) dentre os bons exemplos dessa perspectiva, argumenta que as organizações resistem ao tempo e que as organizações são possuidores de um poder para moldar as ações individuais. Os indivíduos ao ingressarem em uma organização já encontram uma estrutura social, um sistema de normas, valores e expectativas que continuam com sua saída.

Para Custodio, Siqueira, Viegas, Pinto e Silva (2013, p.03) o comprometimento organizacional, em linhas gerais, pode ser entendido como um forte vínculo psicológico do individuo com a organização, que o incita a dar algo de si, a saber, sua energia e lealdade. A relevância dos trabalhadores dentro da organização, segue em foco, assim como seu uso para favorecer os meios de conquistar os objetivos dentro das organizações.

\subsection{Conceitos de Estruturas Organizacionais}

Os objetivos do texto desenvolvido por Griffin e Moorhead (2006) sobre estruturas organizacionais será descrever três tipos de coordenação nas estruturas 
organizacionais; discutir as vantagens e desvantagens da amplitude de controle, centralização e formalização e relacionar esses elementos às estruturas organizacionais orgânicas e mecanicistas; identificar e avaliar seis tipos de departamentalização, e explicar como o ambiente externo, o tamanho da organização, a tecnologia e a estratégia são relevantes quando se projeta uma estrutura organizacional.

Segundo Griffin e Moorhead (2006), a estrutura organizacional é um instrumento importante para guiar e fornecer recursos em relação à estratégia organizacional. Estrutura organizacional se refere à divisão do trabalho e também aos padrões de coordenação, comunicação, fluxo de trabalho e poder formal que norteiam a coordenação, além de ditar quais atividades recebem maior atenção e recursos financeiros, de poder e informação. A estrutura organizacional inclui relações hierárquicas, mas também tem a ver com a concepção das tarefas, o fluxo de informações, as normas e regras de trabalho, a dinâmica de equipe e as relações de poder.

Para Leite e Albuquerque (2013, p.805) a gestão estratégica de pessoas, contemplada como alinhamento sistêmico, depara-se com as abordagens contingencial, universalista, configuracional e cultural. Assim, a estrutura organização é um instrumento importante para a mudança organizacional, pois estabelece novos padrões de comunicação e alinha o comportamento do funcionário com a visão da empresa.

Conclui Leite e Albuquerque (2013, p.805) a abordagem contingencial considera a necessidade de alinhamento da gestão e pessoas a fatores de contingência, tais como ambiente externo, estratégia e cultura organizacional, atribuindo-se, entretanto, uma condição passiva e uma direção linear de adequação do modelo de gestão de pessoas a esses fatores. Contribuindo assim para a estrutura da organização, resultando em termos operacionais aos trabalhadores, na divisão de tarefas.

A divisão do trabalho se refere à subdivisão do trabalho em tarefas distintas atribuídas a pessoas diferentes. Para Griffin e Moorhead (2006), o trabalho subdividido leva à especialização do trabalho porque cada função inclui um conjunto restrito de tarefas necessárias para concluir o produto ou serviço. À medida que as empresas ficam maiores, há uma divisão horizontal do trabalho e por consequência leva a uma divisão vertical: algumas pessoas são designadas para a tarefa de supervisionar, outras são responsáveis por gerir os supervisores e assim por diante. Ainda, segundo Griffin e Moorhead (2006), a especialização do trabalho aumenta a eficiência, pois os ciclos de trabalho são curtos; menos tempo é desperdiçado na passagem para outro; os custos de treinamento são menores porque os funcionários necessitam de menos habilidades física e mental para realizar as tarefas.

Ao dividir o trabalho, há a necessidade de mecanismos de coordenação para garantir a execução articulado da produção. Para Griffin e Moorhead (2006), a coordenação está tão intimamente ligada à divisão do trabalho que o nível ideal de especialização é limitado pela viabilidade de coordenar o trabalho. Por outro lado, a coordenação também tende a se tornar mais cara e difícil à medida que a divisão do trabalho aumenta. Toda organização, seja pequena ou grande, usa um ou mais dos seguintes mecanismos de coordenação: comunicação informal, hierarquia formal e padronização. A comunicação informal inclui o compartilhamento de informações sobre tarefa mútuas e a formação de modelos mentais comuns para que os funcionários sincronizem as atividades de trabalho usando o mesmo roteiro mental. Esse tipo de comunicação funciona melhor na pequena empresa, as organizações 
maiores também incentivam a coordenação pela comunicação informal ao atribuir papéis de colaboração aos funcionários compartilhando informações, como também com o uso das tecnologias da informação. Outra forma para as grandes organizaçõesseria pela organização dos funcionários de vários departamentos em equipes temporárias, ou pela engenharia simultânea que consiste na organização dos funcionários provenientes de vários departamentos em uma equipe temporária com o propósito de desenvolver um produto ou serviço. Na hierarquia formal à medida que a organização cresce, a hierarquia formal passa a ter maior eficácia de comunicação, pois atribui poder legítimo aos indivíduos, os quais utilizam para nortear os processos de trabalho e alocar recursos. Ou seja, o trabalho é coordenado por meio da supervisão direta - a cadeia de comando. A hierarquia formal também coordena o trabalho entre os executivos por meio da divisão das atividades da organização. A padronização envolve a criação de padrões rotineiros de comportamento ou de resultados, a qual formam três formas diferentes: processos padronizados, a qualidade e a consistência de um bem ou serviço podem ser aprimorados mediante descrições e procedimentos de função; habilidades padronizadas quando as atividades de trabalho são complexas demais, as empresas costumam treinar intensamente seus funcionários ou contratando os mais habilidosos; e resultados padronizados, envolve garantir que os indivíduos e as unidades de trabalho tenham objetivos e medidas de resultados claramente definidos.

Segundo Griffin e Moorhead (2006), a estrutura organizacional possui quatro elementos que se aplicam a todas as organizações: amplitude de controle, centralização, formalização e departamentalização. A quantidade de pessoas que se reporta diretamente ao próximo nível de hierarquia é definida como sendo Amplitude de Controle. Ela pode ser estreita quando um número pequeno de pessoa se reporta diretamente a um gestor, enquanto uma amplitude grande muitas pessoas se reportam a um gestor. Para Griffin e Moorhead (2006), as operações de produção com melhor desempenho atualmente se baseiam em equipes autodirigidas, de modo que a supervisão direta (hierarquia formal) é suplantada por outros mecanismos de coordenação, como por meio da comunicação informal e do conhecimento especializado. Outro fator que influencia a melhor amplitude de controle é se os funcionários executam tarefas rotineiras ou o grau de interdependência dos funcionários em um departamento. Portanto, a amplitude de controle está ligada ao tamanho da organização (número de funcionários) e ao número de camadas na hierarquia dessa organização. Griffin e Moorhead (2006)afirmam que os especialistas em organização advertem para as consequências negativas, a longo prazo, do corte excessivo de gestores médios. Essas consequências incluem a debilidade das funções gerenciais necessárias, 0 aumento da carga de trabalho e do estresse entre a gestão e a restrição do desenvolvimento da carreira gerencial. A centralização e a descentralização são elementos importantes quando se projeta uma estrutura organizacional. Segundo Griffin e Moorhead (2006), a centralização significa que a autoridade formal para a tomada de decisão é detida por um pequeno grupo de pessoas, geralmente as que estão no topo da hierarquia organizacional. À medida que as organizações crescem, seus ambientes se tornam mais complexos e a tendência é da organização descentralizar, isto é, dispersar a autoridade decisória e o poder por toda a organização. A formalização é o grau em que as organizações padronizam o comportamento por meio de regras, treinamento formal e mecanismos correlatos, ou seja, as empresas se tornam mais formais à medida que aumentam as formas de 
padronização para coordenar o trabalho. As empresas mais antigas e maiores tendem a se tornarem mais formalizadas, seja porque as atividades de trabalho se tornam mais rotineiras, ou seja, porque a supervisão direta e a comunicação informal entre os funcionários não funcionam com grande quantidade de pessoas. Para Griffin e Moorhead (2006) as influências externas, como a legislação de segurança patrimonial e do trabalho e as regras contábeis rigorosas, são fatores estimulantes à formalização. A formalização pode atéaumentar a eficiência e a obediência, porém pode criar problemas como a aprendizagem e a criatividade organizacional. Griffin e Moorhead (2006)reforçam que o desafio enfrentado pelas empresas quando ficam maiores e mais velhas é evitar o excesso de formalização. Segundo Griffin e Moorhead (2006), os três elementos da estrutura organizacional discutido ate aqui se agrupam em torno de duas formas organizacionais mais amplas, as estruturas mecanicistas e orgânicas. Uma estrutura mecânica se caracteriza por pouca amplitude de controle e alto grau de formalização e centralização. Ao contrário, as estruturas orgânicas possuem grande amplitude de controle, pouca formalização e tomada de decisão descentralizada. Como regra geral, as estruturas mecanicistas funcionam melhor nos ambientes estáveis, já a estruturas orgânicas funcionam melhor nos ambientes que mudam rapidamente porque são mais flexíveis e respondem às mudanças. O quarto elemento da estrutura organizacional o qual específica como os funcionários e suas atividades são agrupadas é chamado de departamentalização. A departamentalização estabelece a cadeia de comando, concentra as pessoas em torno de modelos mentais comuns e estimula determinadas pessoas a coordenarem por meio da comunicação informal. A departamentalização representa os organogramas, Griffin e Moorhead (2006) citam os seis tipos puros de departamentalização mais comuns: simples, funcional, divisional, baseado em equipes, matricial e em rede. A maioria das empresas começa com uma estrutura simples, oferecem apenas um produto ou serviço distinto, hierarquia mínima e altamente flexível. $\mathrm{Na}$ estrutura funcional, os funcionários são organizados em torno de conhecimentos específicos ou de outros recursos, supervisão direta e maior dificuldade agrupar conflitos e de coordenação no atendimento aos clientes ou no desenvolvimento de produtos. A estrutura divisional os funcionários são organizados em torno de áreas geográficas, resultados (produtos/serviços) e clientes. A estrutura baseada em equipes, a estrutura organizacional é criada em torno de equipes autodirigidas que realizam um trabalho completo. Esse tipo de estrutura geralmente é organiza. Há uma grande amplitude de controle, pois as equipes atuam com supervisão mínima. A estrutura baseada em equipes tem conquistado popularidade porque tende a ser flexível e a responder aos ambientes turbulentos. A estrutura matricial reveste duas estruturas a fim de aproveitar os benefícios de ambas. E por último, a estrutura em rede é a aliança de várias organizações com o propósito de criar um produto ou atender um cliente.

Corrobora com este pensamento Rosa (2015, p.187) as transformações da sociedade ao longo dos tempos nos remetem as unidades produtivas, as quais apresentam dimensões reduzidas, medianas e burocratizadas. Estas transformações da sociedade com ampliação e integração do mercado apresentamse no campo da "teoria clássica das organizações". Remetendo-nos a uma visão do todo do processo de estruturação das organizações.

Estes apontamentos realizados pelos autores, mostra com seria a estrutura da organização, nos mostrando suas facetas envolvendo tanto processos internos e focados na divisão do trabalho, quanto às características de processos que 
dependem da existência dos indivíduos dentro da organização, assim como a sua compreensão de todas estas especificações e processos.

\section{CONSIDERAÇÕES FINAIS}

Observamos apartir dos levantamentos necessários à elaboração deste trabalho, o grande apoio das teorias clássicas da administração relacionado a elaboração da cultura organizacional, sendo estás muito utilizadas ainda hoje, mesmo que produzidas no século XX.

Isso demonstra, que mesmo com todo desenvolvimento tecnológico e do campo científico envolvendo os estudos sobre as organizações, não se pode desvencilhar destes apontamentos clássicos, porem verdadeiros, e em muitas situações, dependendo do padrão de estrutura da organização, atuais.

Para Bertero, Vasconcelos, Binder e Wood (2013, p.15) a ecologia organizacional brasileira é complexa, apoiando-se sobre uma economia diversificada e uma textura sociocultural rica e multifacetada. Tal contexto fornece aos pesquisadores, enormes oportunidades para o desenvolvimento da teoria e para 0 aperfeiçoamento da prática administrativa. Como nos faz refletir, os autores indicam que evoluir em relação ao surgimento de novas teorias, assim como teóricos nacionais, demonstrando as realidades das organizações locais, é necessário para a constante evolução desta comunidade científica. 
Concepts of Organizational Theories: literature review

\begin{abstract}
This text is used the literature review technique to make a brief reflection on some of the theorists who portray the theory of organizations as well as the establishment of the organizational structure. There will be a contrast between the thoughts of the interrelation of people, society, organization, all permeated by communication. We brought a brief survey of perspectives on the concepts, as there are in classical literature, numerous theoretical about it. As well as the enhancement of relations between workers and organizations, being key players in the game of organizations, whether any segment of the production chain. We also verified the new readings on these theories, and which today still applies the same within the organization structure. Watching a melting point among new researchers on the need, in the Brazilian case, the emergence of "tropical theories." Suiting the administrative concepts related to Latin American organizations.
\end{abstract}

Keywords: organizacioanis theories; organizational structures and analysis of organizations. 


\section{Referencias}

BASTOS, A. V. B; LOIOLA, E; QUEIROZ, N; SILVA, T. D.. Conceito e perspectivas de estudo das organizações. In: ZANELL, BORGES-ANDRADE, BASTOS E COLS (Org). Psicologia, organizações e trabalho no Brasil. Porto Alegre: Artmed Editora, 2004. p. 63-89.

BERTERO, C.O; VASCONCELOS, F.C.DE; BINDER, M.P, E WOOD, T.JR.. Produção científica brasileira em administração na década de 2000. RAE. 2013. 53(1). 12-20p. Disponível em <http://sistema.semead.com.br/16semead/resultado/trabalhosPDF/1207.pdf>.

CAVALCANTI, M.F.R. E ALCADIPANI, R.. Organizações como processos e teoria atorrede: a contribuição de Jhon Law para os estudos organizacionais. Cadernos EBAPE.br. 2013. 11(4). 556-568p. Rio de Janeiro. Disponível em <http://bibliotecadigital.fgv.br/ojs/index.php/cadernosebape/article/view/8407/13226>.

CUSTODIO, L.S; SIQUEIRA, C.A.A; VIEGAS, G; PINTO, V.N. E SILVA, R.P.DA.. Comprometimento organizacional e estratégia de gestão de pessoas: uma análise das experiências em organizações públicas brasileiras. XVI SEMAD Seminários em Administração.2013. 1-16p. 1 out. $\quad$ Dispível em <http://sistema.semead.com.br/16semead/resultado/trabalhosPDF/1207.pdf>.

GRIFFIN,R. W; MOORHEAD, G.. (Projeto de estruturas organizacionais). In: . Fundamentos do comportamento organizacional. São Paulo, 2006. Cap. 12 e 13, p. 233-296.

LEITE, N.R.P. E ALBUQUERQUE,L.G.. Gestão estratégica de pessoas, estratégia de retenção de profissionais e comprometimento organizacional em uma estrutura organizacional remota. Revista de administração UFSM. 2013. 6(4). 803-822p. Santa Maria. Disponível em <http://revistas.marilia.unesp.br/index.php/novosrumos/article/view/3465/2684>.

MOTTA, L.E.. Os limites teóricos (e políticos) da teoria das organizações e da administração pública. Revista novos rumos. 2013. 50(2). 01-22p. Marilia. Disponível em <http://revistas.marilia.unesp.br/index.php/novosrumos/article/view/3465/2684>.

ROSA, E.C.. Teoria das organizações: o poder no pensamento de Michel Foucault, com um olhar na universidade. Revista triangulo. 2015. 8(2). 185-194p. jul./dez. Disponível em <http://seer.uftm.edu.br/revistaeletronica/index.php/revistatriangulo/article/view/1693/1545>.

SILVA, Clóvis L. Machado da; FONSECA, V. S.. Estruturação da estrutura organizacional: o caso de uma empresa familiar. O\&S. Organizações \& Sociedade, Salvador, v. 1, n.1, p. 42-71, 1993. ISSN/ISBN: 1413585X. 